\title{
Photo-curing kinetics of hydroxyethyl acrylate (HEA): synergetic effect of dye/amine photoinitiator systems
}

\author{
Nouria Bouchikhi ${ }^{1,2} \cdot$ Manel Bouazza $^{2} \cdot$ Salah Hamri ${ }^{1,2}$. Ulrich Maschke ${ }^{3}$. Djahida Lerari ${ }^{1}$. Faycal Dergal ${ }^{1}$. \\ Khaldoun Bachari ${ }^{1}$. Lamia Bedjaoui-Alachaher ${ }^{2}$
}

Received: 27 September 2018 / Accepted: 3 December 2019 / Published online: 17 December 2019

(c) The Author(s) 2019

\begin{abstract}
The aim of this study is to examine and evaluate several dye/amine systems as photoinitiators for photopolymerization of 2-hydroxyethyl acrylate (HEA) monomer under visible light conditions. For this purpose, a series of dye/amine photoinitiators were formed using methylene blue $(\mathrm{MB})$ or acridine orange $(\mathrm{AO})$ as photosensitizers, and triethanolamine (TEOA), ethyl 4-(dimethylamino) benzoate (EDMAB), trioctylamine (TOA), and N,N-diméthylallylamine (DMAA) as co-initiators. The photopolymerization kinetic of the HEA monomer in the presence of proposed dye/amine systems was performed using Fourier-transform infrared spectroscopy (FTIR) analysis and the synergetic effect of the dye/amine photoinitiators systems on the photopolymerization efficiency was examined. Interestingly, (MB/EDMAB) system shows the better reactivity with a total conversion of HEA monomer.
\end{abstract}

Keywords Dye $\cdot$ Amine $\cdot$ Visible light $\cdot$ Phototransformation $\cdot$ Photopolymerization

\section{Introduction}

Visible light-activated photoinitiators (VALP's) have received considerable attention owing to their involvement in visible light-induced polymerization. The attractiveness and potential use of visible light in material science steam essentially from its harmless character and higher penetration ability as compared for example with UV light $[1,2]$.

Indeed, from a polymer chemistry perspective, photopolymerization using visible light offers a plethora of advantages encompassing solvent-free formulation, rapid curing at ambient temperature and appealing cost-effective bias that have led to broad application in industrial fields such as

Nouria Bouchikhi

noura.bouchikhi@yahoo.fr

1 Centre de Recherche Scientifique et Technique en Analyses Physico-chimiques, BP 384, Zone Industrielle Bou-ismail, RP 42004 Tipaza, Algeria

2 Laboratoire de Recherche sur les Macromolécules, Faculté des Sciences, Université de Tlemcen, BP119, 13000 Tlemcen, Algeria

3 Unité Matériaux et Transformations UMET (UMR CNRS N_8207) Bâtiment C6, Université Lille 1-Sciences et Technologies, 59655 Villeneuve d'Ascq, France pigmented coatings, paints, dental adhesives, holographic records, inks and electronics [3-5].

As far as photopolymerization is concerned, a careful selection of the photoinitiator (PI) is crucial to this process. Two types of PI are currently used. TypeI photoinitiator, in which a hemolytic cleavage of its species is taking place, triggers the free radical formation and hence, the initiation of the photopolymerization. In type II, where in the generally accepted mechanism more than two species are involved, the radicals are formed by an electron transfer reaction succeeded by hydrogen transfer between a photosensitizer (PS) and a co-initiator [6].

As a typical example of typeII photoinitiator, VALP's are generally based on a combination of a carbogenic dye acting as PS and an amine-bearing compound as co-initiator [7-9]. In some cases, addition of electron acceptors such as iodonium or sulfonium salts to the mixture has been reported in the literature [10-12].

In as much, the photosensitization step is determining for subsequent evolution of the polymerization process as whole, practical requirements ought to be implemented for achieving high conversion rates. These include: (i) good miscibility of PI with monomers, (ii) maximum light absorption, (iii) high quantum yield coupled to long lifetime of the triplet state and, (iv) excellent hydrogen-donating character of 
the co-initiator. In other words, of the four above-mentioned requirements, three are of physical nature and only (iv) is chemically driven parameter $[13,14]$.

As application of these concepts, photopolymerization using LED's as visible light source has been recently reported. A remarkable enhancement of light absorbance as well as improved efficiency of VALP's was achieved through the use of panchromatic visible light irradiation $[15,16]$. In a forward move, high monomer conversion rates for both cationic and radical photopolymerization were reported by a subtle combination of LED's and redox systems [6, 17]. However, chemical hazards inherent to the use of powerful oxidizing agents in polymerization processes have severely limited the generalization of this option, even though a soft redox system based on copper complex-phosphine interaction was introduced for methacrylate polymerization [18].

From a literature survey, notwithstanding the impressive efforts that were devoted to implement a safe and efficient photopolymerization using visible laser or LED's, all of which are grouped in physical type strategies, a reliable chemical approach based on a careful selection of dye/amine (PS system) deserves to be considered.

In an attempt to investigate the efficiency of dye/amine couple as PI system in the photopolymerization of hydroxyl ethyl acrylate (HEA) under visible light irradiation in soft condition (halogen lamp, air atmosphere), we have prepared five PI couples, namely MB/TEOA, AO/TEOA, MB/ DMAA, MB/TAO and MB/EDMAB. The photochemical behavior of $\mathrm{MB}$ and $\mathrm{AO}$ were first evaluated by UV-Visible spectroscopy. In the next task, we turned our attention to the selection of PI, by focusing on the synergistic effect between PS and its amine co-initiator partner. In each case, HEA polymerization was monitored by FTIR. The conversion yield is discussed in terms of PI system chemical combination.

\section{Materials and methods}

\section{Reagents and chemicals}

All the reactants were used as received and are shown in Fig. 1. 2-Hydroxyethyl acrylate (HEA), methylthioninium chloride (methylene blue MB), 3- $N, 3-N, 6-N, 6-N$ tetramethylacridine-3,6 diamine (acridine orange $\mathrm{AO}$ ), triethanolamine (TEOA), $N, N$-dimethylallylamine (DMAA), trioctylamine (TOA) and ethyl 4- (dimethylamino) benzoate (EDMAB) were purchased from Aldrich.

\section{Instrumentation and characterization}

Absorption spectra of dyes and photoinitiator systems (dye/ amine) were recorded on Agilent Cary 60 UV-Visible (a)<smiles>C=CC(=O)OCCO</smiles>

(b)<smiles>CN(C)c1ccc2nc3ccc(N(C)C)cc3[s+]c2c1</smiles>

(c)<smiles>CN(C)c1ccc2cc3ccc(N(C)C)cc3nc2c1</smiles>

(d)<smiles>OCCN(CCO)CCO</smiles>

(e)<smiles>C=CCN(C)C</smiles>

(f)<smiles>CCCCCCCCN(CCCCCCCC)CCCCCCCC</smiles>

(g)<smiles>CCOC(=O)c1ccc(N(C)C)cc1</smiles>

Fig. 1 Chemical structures of reagents. a HEA, b MB, c AO, d TEOA, e DMAA, f TOA, g EDMAB 
spectrophotometer, using distilled water as solvent. To study the photoreactivity of dyes in the presence of amine molecule, a set of experiments with dye/amine ratio of $(0.01 / 3$ $\mathrm{wt} \%$ ) were conducted at different times.

The polymerization of HEA photoinitiated with different photoinitiator (PI) systems was conducted on Agilent cary 640 instruments FTIR spectrophotometer, at $2 \mathrm{~cm}^{-1}$ resolution with 32 scans over the spectral range of $4000-400 \mathrm{~cm}^{-1}$. The photosensitive formulations were deposited on a $\mathrm{CaF} 2$ pellet for irradiation with halogen lamp $\left(\lambda>400 \mathrm{~nm}, I_{0}=20\right.$ $\mathrm{mw} / \mathrm{cm}^{2}$ ), under air atmosphere. The polymerization evolution was monitored by FTIR spectroscopy, on the basis of Eq. 1, by following the decrease of the peak at $1635 \mathrm{~cm}^{-1}$, assigned to the acrylic double bond of the HEA monomer.

$\operatorname{Conv}(\%)=\frac{A_{0}-A_{t}}{A_{0}} \times 100$,

where $A_{0}$ is the initial absorbance at $1635 \mathrm{~cm}^{-1}$ and $A_{\mathrm{t}}$ the absorbance value at irradiation time $t$.

A DSC Q2000 from TA Instruments was used for differential scanning calorimetry (DSC) analyses under nitrogen atmosphere. Samples of 5-7 mg were sealed in aluminum pans and placed in the DSC cell; the samples were then heated from -70 to $100{ }^{\circ} \mathrm{C}$ at a heating rate of $10{ }^{\circ} \mathrm{C} / \mathrm{min}^{-1}$ under nitrogen flow. Transition temperature $(\mathrm{Tg})$ values were collected from the second heating scan.

\section{Results and discussion}

In this contribution, several combinations of dyes/amines were tested as photoinitiator for the polymerization of HEA under visible light. For this purpose, four amines (TEOA, DMAA, TOA and EDMAB) (see Fig. 1) were used as coinitiators in the presence of two photosensitizers (MB and $\mathrm{AO})$. Before starting the photopolymerization experiments, the response of PIs towards the visible light irradiation was examined. The phototransformation of $\mathrm{MB}$ and $\mathrm{AO}$ alone and in the presence of TEOA was followed by means of UV-Vis spectrophotometry. Photopolymerization kinetic was then assessed by varying the composition of PI system. Finally, the effect of PI on the transition temperature $(\mathrm{Tg})$ of obtained polymers is highlighted in last section of this paper.

\section{Phototransformation of MB and AO}

Before tackling the issue of amine effect on the photoinitiation step of HEA polymerization, a preliminary examination of PS response to visible light irradiation was considered. An aqueous solution of each dye was irradiated at different times and examined by means of
UV spectroscopy. A graphical plot correlating the absorbance of MB to irradiation time is illustrated in Fig. 2. The spectrum shows the presence of two bands, the most intense of which is centered at $665 \mathrm{~nm}$ and is assigned to the $n-\pi^{*}$ transition. The second at $600 \mathrm{~nm}$ is attributed to the $0-1$ vibronic transition $[19,20]$. However, their absorbance decreased gradually upon increasing irradiation time (Fig. 2). This decrease in absorbance is attributed to the photoreduction of MB in the presence of oxygen which acts as electron donor, leading to the formation of the leuco form of dye molecules (colorless MB) [21-23]. It was also reported that the photobleaching of MB can be due to the presence in methylene blue of amine groups that act as electron donors in the absence of other reducing agents [10].

Interestingly, Fig. 3 shows that in the presence of TEOA, a sharp drop in absorbance occurred within 3 min of irradiation, corresponding to a rate of $84 \%$ of radical formation (photoreduction), while in the absence of TEOA, a conversion of only $37 \%$ of MB was observed after 120 min of irradiation (Fig. 2). From a mechanistic point of view, in the presence of TEOA, an electron is transferred from the amine to MB producing a semi-reduced dye radical. Then, the MB dye molecule is photo-reduced by hydrogen abstraction of from the amine, to produce amine and dye radicals [24-26]. In other words, the conversion of MB in the presence of an amine is the result of an electron transfer from TEOA to MB that is excited to a triplet state whose lifetime is estimated at $450 \mu$ s [27].

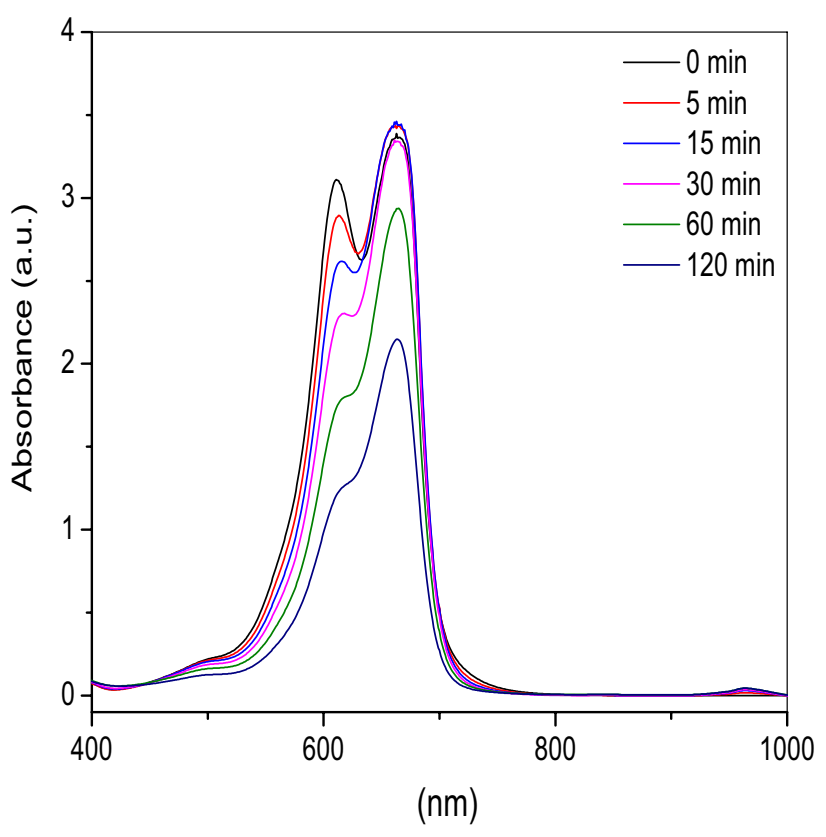

Fig. 2 UV-Visible spectra of MB dye $([c]=0.01 \mathrm{~g} / \mathrm{l})$, at different irradiation time 


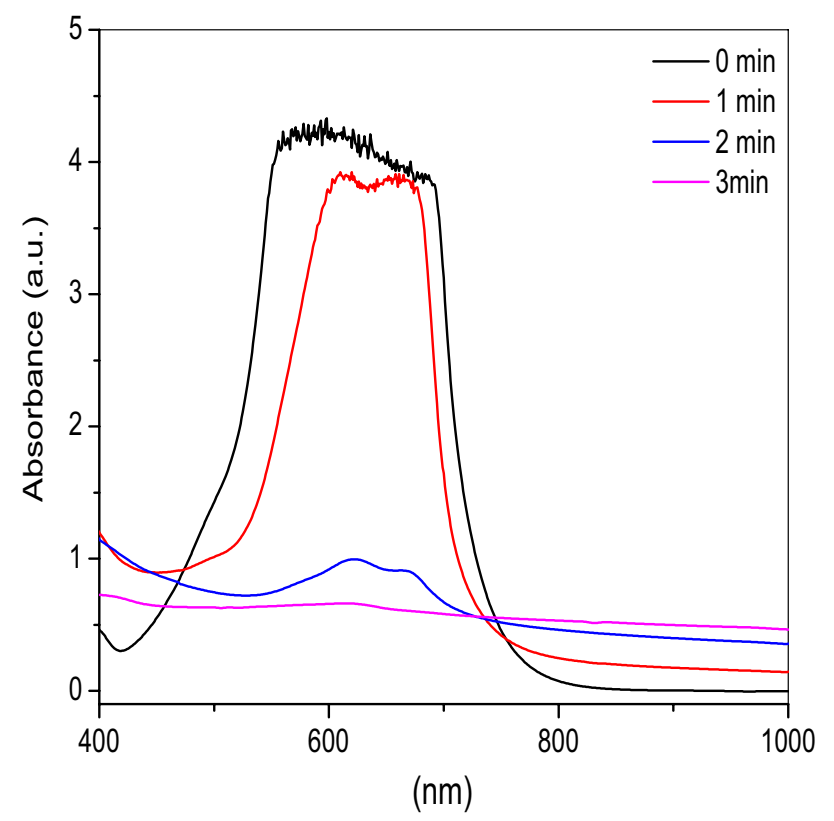

Fig. 3 UV-Visible spectra of MB/TEOA $(0.01 / 3 \mathrm{wt} \%)$ photoinitiator system, at different irradiation time

Similarly, we have addressed the use of AO dye as photosensitizer. The evolution of AO's main absorption band centered at $475 \mathrm{~nm}$, in the absence and in the presence of TEOA, is illustrated in Fig. 4 and Fig. 5, respectively.

The absorption of dye decreases upon prolonged exposure to visible light irradiation. A rate of $75 \%$ phototransformation of $\mathrm{AO}$ is observed after $60 \mathrm{~min}$ of irradiation, revealing

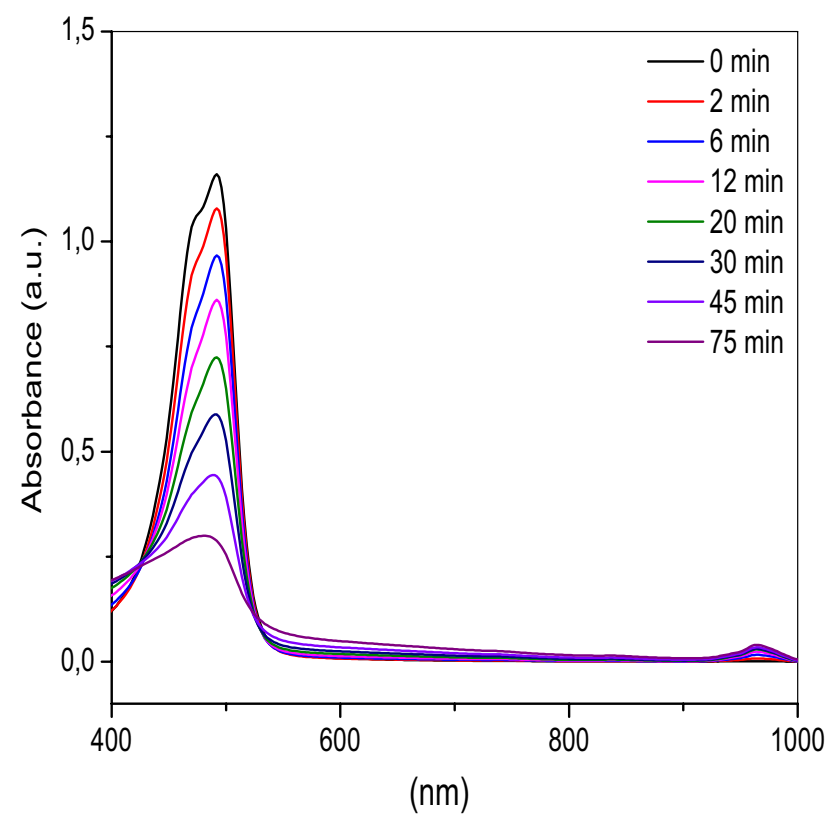

Fig. 4 UV-Visible spectra of AO dye $([c]=0.01 \mathrm{~g} / \mathrm{l}]$, at different irradiation time

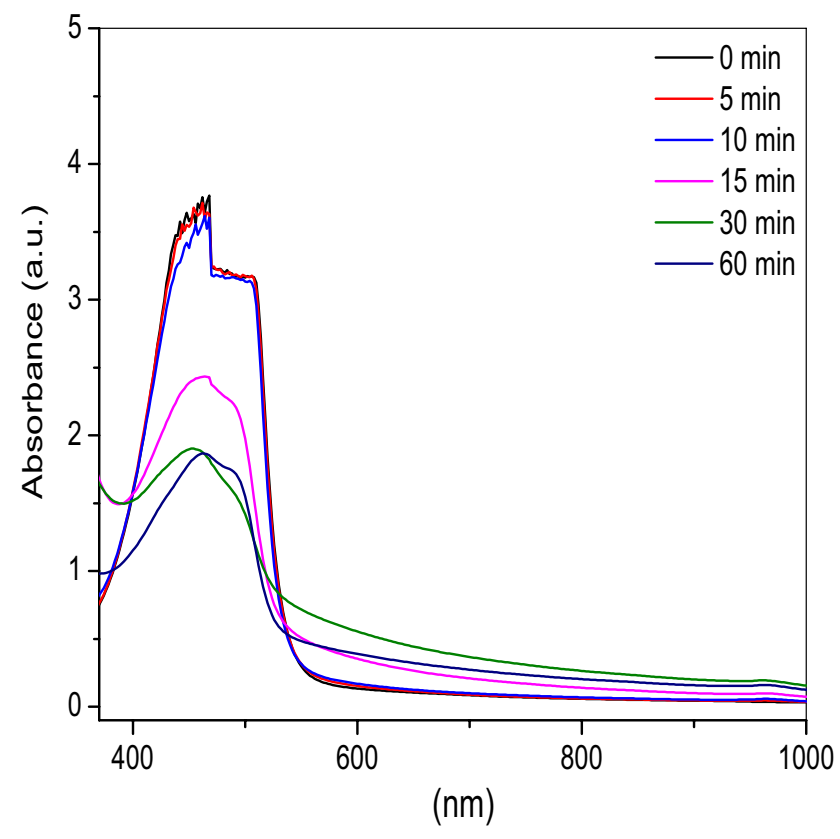

Fig. 5 UV-Visible spectra of AO/TEOA (0.01/3wt\%) photoinitiator system, at different irradiation time

a fairly high conversion of $\mathrm{AO}$ molecules to the triplet state [28]. However, in the presence of amine, 38\% of phototransformation is noticed. This is as cribbed to a short-lived $\mathrm{AO}$ excited triplet state $(t=50 \mu \mathrm{s})$ and the occurrence of a triplet-triplet electron-transfer process, which decreases the photo-reduced dye molecules [26, 29]. Figure 6 underlines the phototransformation mechanism of these dyes in presence of TEOA.

The evolution of HEA photopolymerization in the presence of MB/TEOA or AO/TEOA $(0.01 / 3 \mathrm{wt} \%)$ was examined for different irradiation times. The monomer conversion plots versus time are depicted in Fig. 7a, b.

In the presence of $\mathrm{MB}$, a monomer conversion of about $100 \%$ is noticed, while that in the presence of $\mathrm{AO}$ is $95 \%$ at 30 min of irradiation (Fig. 7a).

The photoinitiation mechanism in the presence of $\mathrm{MB} /$ TEOA or AO/TEOA involves the electron transfer, followed by a proton transfer from the tertiary amine to the dye leading to the formation of amine radical (TEOA.), which will initiate the polymerization, and the dye radical which acts as a terminating agent $[12,30]$.

Figure $7 \mathrm{~b}$ shows that the monomer conversion is about $90 \%$ in the first $35 \mathrm{~s}$ of irradiation, when $\mathrm{AO}$ photosensitizer is used, whereas is about $40 \%$ in the case of MB. This result can be assigned to the rapid reduction of $\mathrm{AO}$ in the presence of TEOA which is due to a total triplet-state conversion of AO molecules [28].

In that case, many radicals are quickly formed, but their efficiency to initiate the polymerization of HEA 
Fig. 6 Phototransformation reaction of $\mathrm{MB}$ and $\mathrm{OA}$ dyes in the presence of TEOA

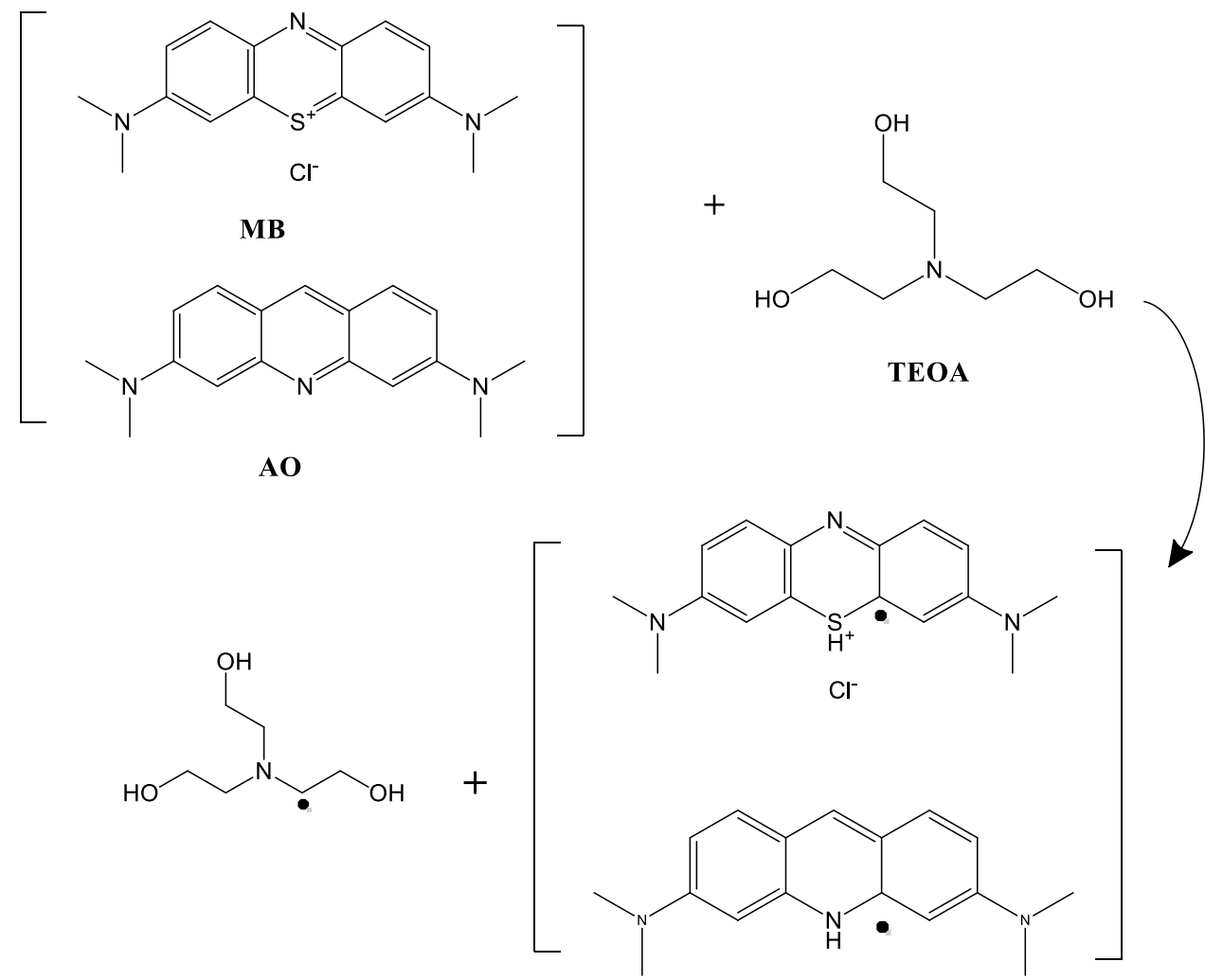

may be conditioned by their short-lived triplet-state time $(t=50 \mu \mathrm{s})$. Furthermore, many hydroxyl ethacrylate radicals can be formed (HEA.), leading to the formation of short polymer chains or oligomers. However, the conversion evolution of HEA monomer in presence of $\mathrm{MB}$ is slow, which is related to long live time of triplet state ( $450 \mu \mathrm{s}$ ), and the probability that the hydroxyethyl acrylate radical (HEA.) is added on growing macroradical HEA.is more important. In this case, the PHEA undergoes a longer polymer chains.

\section{Synergy between MB dye and co-initiators}

To underline the effect of co-initiator nature on the HEA monomer conversion, the MB dye was selected as photosensitizer. Figure 8a depicts the evolution of this conversion in the presence of the four co-initiator selected in this study.

It can be deduced from Fig. $8 \mathrm{a}$ that in all systems, the monomer conversion increases by increasing the irradiation time until reaching a maximum value. It appears also that the efficiency of the dye/amine photoinitiator depend markedly on the chemical structure of amine. During the electron-proton transfer between the excited photosensitizer and the hydrogen donors, both active radical moieties and photosensitizer radicals are generated. It has been reported that the use of tertiary amine in visible light-induced polymerization under air is important not only to initiate polymerization but also to eliminate or reduce the oxygen inhibition. The process involves the reaction of formed amine radicals with molecular oxygen; this reaction is faster than that with active radicals, which lead to the continuous consumption of oxygen [31, 32].

It is important to note that for time ranging $0-10 \mathrm{~s}$ (Fig. 8b), the monomer conversion is in the range of $25-40 \%$, with a remarkable evolution of the conversion in the presence of TEOA. After 5 min of irradiation, the formulation containing the EDMAB underlines a monomer conversion exceeding $95 \%$, whereas in the case of TEOA, this conversion is less than $80 \%$. In the case of DMAA and TOA a conversions of $60 \%$ and $40 \%$ were noticed, respectively. This difference is relied to the stability of amine radicals formed during the phototransformation step.

The curing mechanisms are shown in Fig. 9.

After irradiation, the excited dye reacts with amine to form the amine radical cation, this reaction is followed by proton transfer from the amine to the dye, leading to the formation of free radical active center capable to initiate polymerization, and the dye radicals act as terminating agents, according to the reaction below:

$\mathrm{Dye}^{*}+\mathrm{R}_{3} \mathrm{~N}: \stackrel{+\mathrm{e}^{-}}{\longrightarrow} \mathrm{Dye}^{-}+\mathrm{N}^{+\cdot} \stackrel{+\mathrm{H}^{+}}{\longrightarrow}$ Dye $+\mathrm{A}$. 

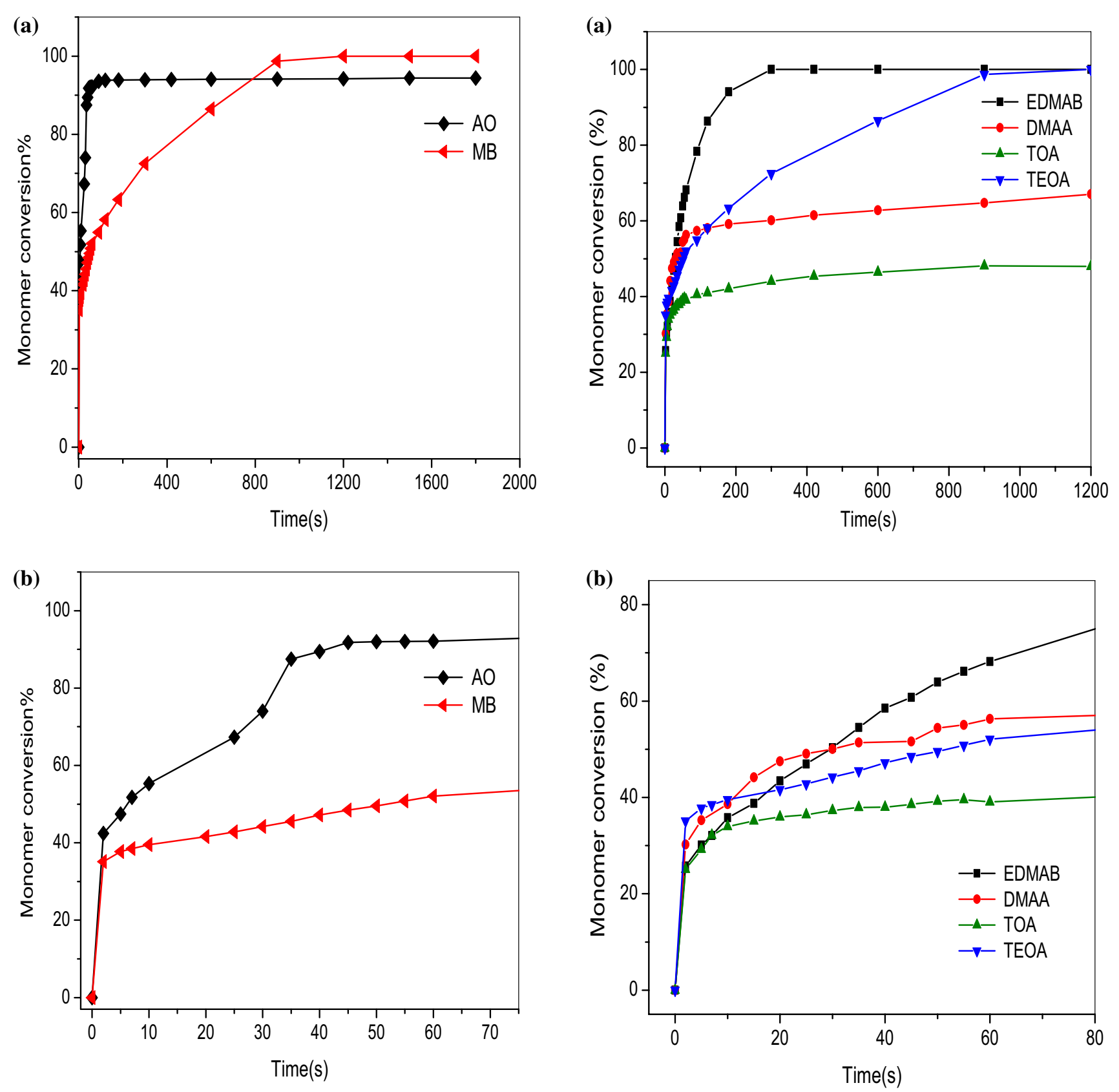

Fig. 7 a HEA monomer conversion (\%) versus irradiation time in the presence of TEOA co-initiator, $\mathbf{b}$ enlargements of (a)

It has been reported that the efficiency of amine as coinitiator depends on the radical cation persistence and the proton transfer ability [30,33]. More the proton transfer is delayed more the radical cation is persistent.

In the case of TOA, the difficulty of losing a proton due to its bulky substituents, leads to the formation of highly persistence radical cation.

Fig. 8 a Monomer conversion as function of time in the presence of different MB/amine systems, $\mathbf{b}$ enlargements of (a)

In addition of the proton transfer process, the photoinitiation efficiency depends also on the stability and architecture of amine radicals. Comparing the systems containing EDMAB and TEOA, the more efficient system is EDMAB/ $M B$, because the radical formed in the case of EDMBA is more free that in the case of TEOA. In the case of DMAA, the amine radical is less stable due to the mesomeric effect. 
Fig. 9 Photoinitiation mechanism in the presence of different $\mathrm{MB} / \mathrm{amine}$ systems<smiles>CN(C)C1=CC2[Se]c3cc(N(C)C)ccc3N=C2C=C1</smiles>

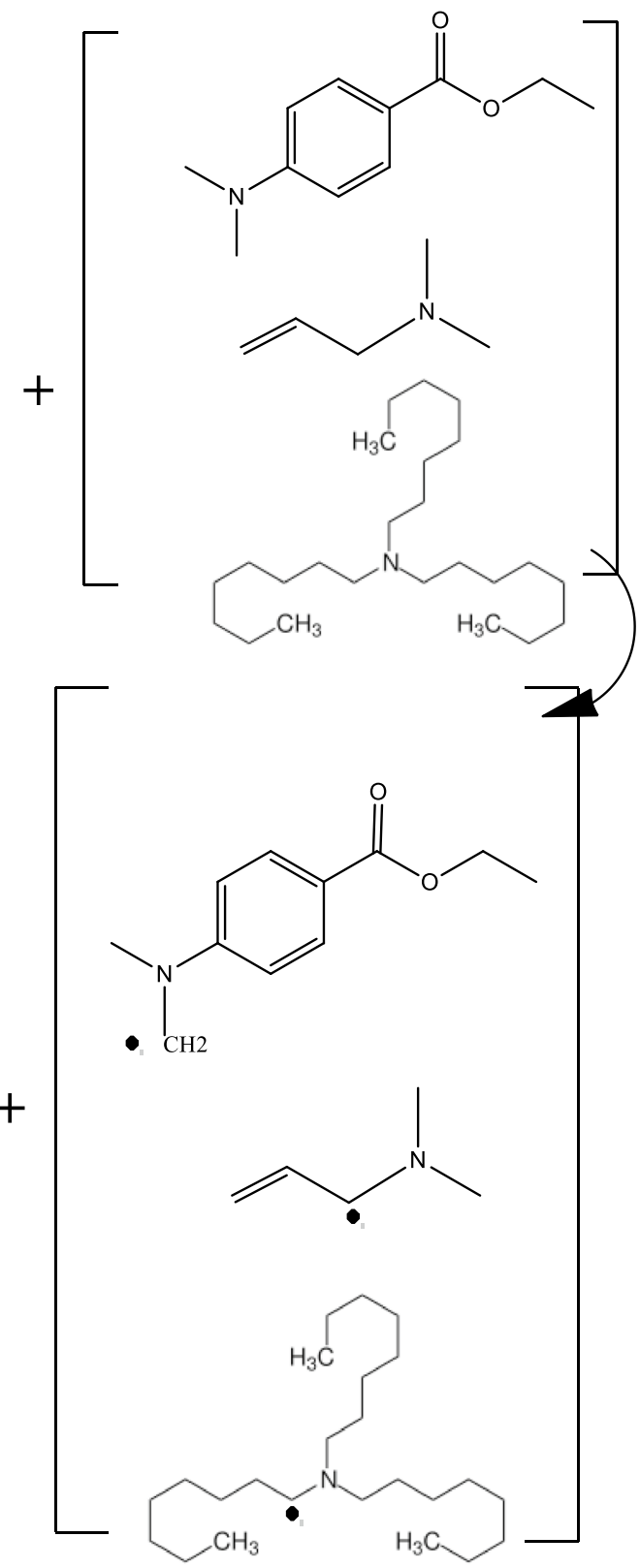

Hence, the order of efficiency of amines as co-initiator is EDMAB $>$ TEOA $>$ DMAA $>$ TOA.

To show the effect of the dye and the amine natures on the glass transition temperatures ( $\mathrm{Tg}$ ) the obtained polymers were characterized by DSC. Figure 10 shows thermograms from DSC measurements of the obtained polymers in the presence of different dye/amine systems.

It is noted that the choice of dye/amine systems has an effect on the glass transition temperature of polyHEA. Further thermal studies will be conducted to better understand this effect.

\section{Conclusion}

In this study, we investigated the photopolymerization reaction induced by the visible light, in the presence of different photoinitiators dye/amine systems under soft conditions. The phototransformation kinetic of the different dyes in the absence and in the presence of amine was carried out by UV-Visible spectrophotometer. The two dyes $\mathrm{OA}$ and $\mathrm{MB}$ showed a strong decrease of their absorption bands in the visible by becoming colorless. The photopolymerization of HEA in the presence of AO and MB showed that the important conversion percentage was obtained with MB dye. To analyze the effect of electron 


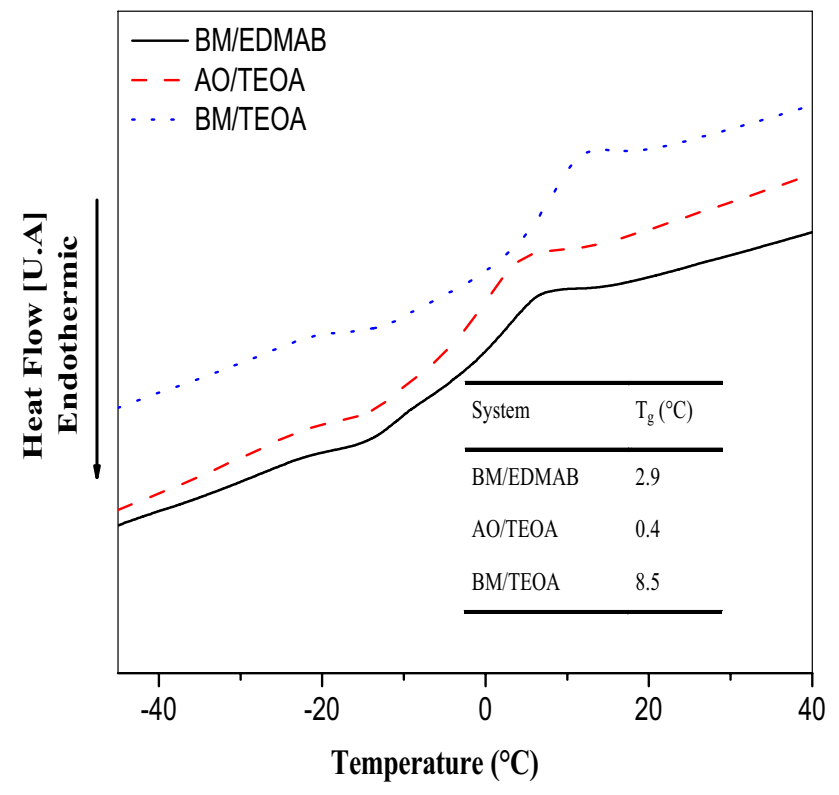

Fig. 10 Thermograms of polyHEA in the presence of different photoinitiating systems

donor structure on the polymerization, four amines were proposed, and the most efficient one is EDMAB.

Acknowledgements We gratefully acknowledge Dr. Ziani Cherif Hocine, professor at the university Abou Bakr Belkaid of Tlemcen for his expert advice, help and encouragement.

Open Access This article is licensed under a Creative Commons Attribution 4.0 International License, which permits use, sharing, adaptation, distribution and reproduction in any medium or format, as long as you give appropriate credit to the original author(s) and the source, provide a link to the Creative Commons licence, and indicate if changes were made. The images or other third party material in this article are included in the article's Creative Commons licence, unless indicated otherwise in a credit line to the material. If material is not included in the article's Creative Commons licence and your intended use is not permitted by statutory regulation or exceeds the permitted use, you will need to obtain permission directly from the copyright holder. To view a copy of this licence, visit http://creativecommons.org/licenses/by/4.0/.

\section{References}

1. Chełminiak D, Ziegler-Borowska M, Kaczmarek H (2016) Synthesis of magnetite nanoparticles coated with poly (acrylic acid) by photopolymerisation. Mater Lett 164:464-467. https://doi. org/10.1016/j.matlet.2015.11.023

2. Hamri S, Bouchaour T, Maschke U (2014) Erythrosine/triethanolamine system to elaborate crosslinked poly(2-hydroxyethyl methacrylate):UV-photopolymerisation and swelling studies. Macromol Symp 336:75-81. https://doi.org/10.1002/ masy. 201300018

3. Kasapoglu F, Aydin M, Arsu N, Yagci Y (2003) Photoinitiated polymerization of methyl methacrylate by phenacyl type salts. J
Photochem Photobiol A 159:151-159. https://doi.org/10.1016/ S1010-6030(03)00180-1

4. Liu Y, Wang Y (2013) Effect of proanthocyanidins and photoinitiators on photo-polymerization of a dental adhesive. J Dent 41:71-79. https://doi.org/10.1016/j.jdent.2012.10.006

5. Nan X, Sun G, Huang Y, Fan Q, Yao Y, Shao J (2015) Photoinitiating characteristic of erythrosine $\mathrm{B}$ derivatives and its application on pigmented visible photo-curing ink of textile digital printing. Text Res J 86:2158. https://doi.org/10.1177/00405 17515621133

6. Fouassier JP, Lalevée J (2012) Photoinitiators for polymer synthesis: scope, reactivity, and efficiency. Wiley-VCH Verlag $\mathrm{GmbH} \&$ Co KgaA, Germany

7. Bibaaut-Renauld C, Burget D, Fouassier JP, Varelas CG, Thomatos J, Tsagaropoulos G, Ryrfors LO, Karlsson OJ (2002) Use of $\alpha$-diketones as visible photoinitiators for the photocrosslinking of waterborne latex paints. J Polym Sci Part A Polym Chem 40:3171-3181. https://doi.org/10.1002/pola.10407

8. Pyszka I, Kucybala Z, Paczkowski J (2003) Development of new dyeing photoinitiators based on benzylideneimidazopyridine dyes. J Polym Sci Part A Polym Chem 41:3048-3055. https:// doi.org/10.1002/pola.10891

9. Crivello J, Ahn J (2003) Synthesis and characterization of secondgeneration S, S-dialkyl-S-(dimethylhy droxyphenyl) sulfonium salt photoinitiators. J Polym Sci Part A Polym Chem 41:25562569. https://doi.org/10.1002/pola.10801

10. Padon KS, Scranton AB (2000) A mechanistic study investigation of a three componentradical photoinitiator system comprising methylene $N$-methyldiethanolamine and diphenyliodonium chloride. J Polym Sci Part A Polym Chem 38:2057-2066. https ://doi.org/10.1002/1099-0518(20010301)39:5\%3c715:AIDPOLA1043\%3e3.3.CO;2-F

11. Padon KS, Kim D, El-Maazawi M, Scranton AB (2003) Spectroscopic investigation of three-component initiator systems. ACS Symp Ser 847:15-26. https://doi.org/10.1021/bk-20030847.ch002

12. Kim D, Scranton A (2004) The role of diphenyl iodonium salt (DPI) in three-component photoinitiator systems containing methylene blue (MB) and an electron donor. J Polym Sci Part A Polym Chem 42:5863-5871. https://doi.org/10.1002/pola.20426

13. Zhang J, Frigoli M, Dumur F, Xiao P, Ronchi L, Graff B, Morlet-Savary F, Fouassier JP, Gigmes D, Lalevée J (2014) Design of novel photoinitiators for radical and cationic photopolymerizations under near UV and visible LEDs (385, 395 and $405 \mathrm{~nm})$. Macromolecules 47:2811-2819. https://doi.org/10.1021/ma500 $612 \mathrm{x}$

14. Bouzrati-Zerelli M, Zivic N, Dumur F, Gigmes D, Graff B, Fouassier JP, Lalevée J (2017) New violet to yellow light sensitive diketo pyrrolo-pyrrole photoinitiators: high performance systems with unusual bleaching properties and solubility in water. Polym Chem 8:2028-2040. https://doi.org/10.1039/ C7PY00202E

15. Zhang J, Lalevée J, Hill NS, Launay K, Morlet-Savary F, Graff B, Stenzel MH, Coote ML, Xiao P (2016) Disubstituted aminoanthraquinone-based multicolor photoinitiators: photoinitiation mechanism and ability of cationic polymerization under blue, green, yellow, and red LEDs. Macromolecules 51:208165-208173. https ://doi.org/10.1021/acs.macromol.8b01763

16. Zhang J, Launay K, Hill NS, Zhu D, Cox N, Langley J, Lalevée J, Stenzel MH, Coote ML, Xiao P (2018) Disubstituted aminoanthraquinone-based photoinitiators for free radical polymerization and fast 3D printing under visible light. Macromolecules. https:// doi.org/10.1021/acs.macromol.8b02145

17. Garra P, Morlet-Savary F, Dietlin C, Fouassier JP, Lalevée J (2016) On-demand visible light activated amine/benzoyl peroxide redox initiating systems: a unique tool to overcome the shadow 
areas in photopolymerization processes. Macromolecules. https:// doi.org/10.1021/acs.macromol.6b02167

18. Garra P, Dumur F, Morlet-Savary F, Dietlin C, Fouassier JP, Lalevée J (2016) a new highly efficient amine-free and peroxidefree redox system for free radical polymerization under air with possible light activation macromolecules. Macromolecules. https ://doi.org/10.1021/acs.macromol.6b01615

19. Heger D, Jirkovsky J, Kln P (2005) Aggregation of methylene blue in frozen aqueous solutions studied by absorption spectroscopy. $\mathrm{J}$ Phys Chem A 109:6702. https://doi.org/10.1021/jp050439j

20. Bergmann K, O'Konski CT (1963) A spectroscopic study of methylene blue monomer, dimer, and complexes with montmoriUonite. J Phys Chem 67:2169-2177. https://doi.org/10.1021/j100804a04 8

21. Solano C, Lessard RA, Roberge PC (1987) Methylene blue sensitized gelatin as a photosensitive medium for conventional and polarizing holography. Appl Opt 26:1989-1997. https://doi. org/10.1364/AO.26.001989

22. Severino D, Junqueira HC, Gabrielli DS, Gugliotti M, Baptista MS (2003) Influence of negatively charged interfaces on the ground and excited state properties of methylene blue. Photochem Photobiol 77:459-468. https://doi.org/10.1562/0031-8655(2003)07704 59IONCIO2.0.CO2

23. DeRosa MC, Crutchley RJ (2002) Photosensitized singlet oxygen and its applications. Coord Chem Rev 233:351-371. https://doi. org/10.1016/S0010-8545(02)00034-6

24. Jain K, Klier J, Scranton AB (2005) Photopolymerization of butyl acrylate-in-water microemulsions: polymer molecular weight and end-groups. Polymer 46:11273-11278. https://doi.org/10.1016/j. Polymer.2005.09.065

25. Valdebenito A, Encinas MV (2008) Chain transfer agents in vinyl polymerizations photoinduced by bimolecular photo initiators. J Photochem Photobiol A Chem 194:206-211. https://doi. org/10.1016/j.jphotochem.2007.08.012

26. Encinas MV, Rufs AM, Bertolotti SG, Previtali CM (2009) Xanthene dyes/amine as photoinitiators of radical polymerization: a comparative and photochemical study in aqueous medium. Polymer 50:2762-2767. https://doi.org/10.1016/j.polymer.2009.04.024

27. Mills A, Wang J (1999) Photobleaching of methylene blue sensitised by TiO2: an ambiguous system? J Photochem Photobiol A 127:123-134. https://doi.org/10.1016/S1010-6030(99)00143-4

28. Kellmann A (1971) a flash photolysis study of the triplet state of acridine orange in basic solvents. Photochem Photobiol 14:85-93. https://doi.org/10.1111/j.1751-1097.1971.tb06155.x

29. Kellman A (1974) Primary photochemical processes of cationic acridine orange in aqueous solution studied by flash photolysis. Photochem Photobiol 20:101-108. https://doi. org/10.1111/j.1751-1097.1974.tb06556.x

30. Kim D, Scranton AB, Stansbury JW (2009) Effect of the electron donor structure on the shelf-lifetime of visible-light activated three-component initiator systems. J Appl Polym Sci 114:15351542. https://doi.org/10.1002/app.30770

31. Fouassier JP, Allonas X, Burget D (2003) Photopolymerization reactions under visible lights: principle, mechanisms and examples of applications. Prog Org Coat 47:16-36. https://doi. org/10.1016/S0300-9440(03)00011-0

32. Balta DK, Karasu F, Aydın M, Nergis A (2007) The effect of the amine structure on photoinitiated free radical polymerization of methyl methacrylate using bisketo coumarin dye. Prog Org Coat 59:274-277. https://doi.org/10.1016/j.porgcoat.2007.03.005

33. Padon SK, Scranton AB (2000) The effect of oxygen on the three-component radical photoinitiator system: methylene blue, $\mathrm{N}$-methyldiethanolamine, and diphenyliodonium chloride. J Polym Sci Polym Chem 38:3336-3346. https://doi.org/10.1002/10990518(20000915)38:18\%3c3336:AID-POLA110\%3e3.0.CO;2-3

Publisher's Note Springer Nature remains neutral with regard to jurisdictional claims in published maps and institutional affiliations. 